
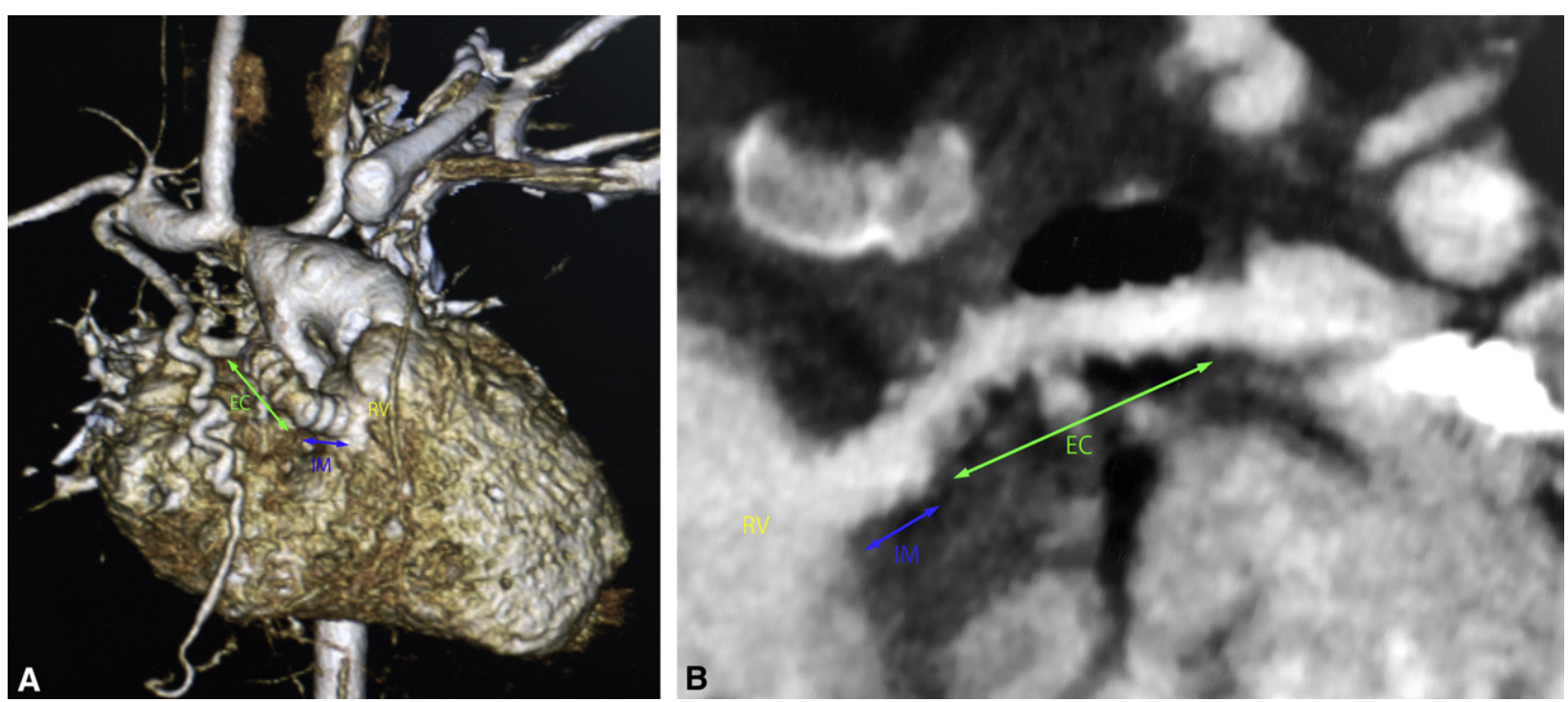

FIGURE 3. Follow-up computed tomography angiocardiogram in a patient 10 months after surgery showing the widely open proximal anastomosis and no ventricular pseudoaneurysm formation. A, Multidetector volume-rendering image (front view). B, Multiplanar reconstruction image of the conduit lumen. $E C$, Extracardiac portion of the conduit; $I M$, intramural portion of the conduit; $R V$, right ventricle.

make the creation of conduit inflow technically easier, minimally time-consuming, and highly reproducible, and minimize the risk of several potential ventriculotomyrelated complications, which augments an inherent advantage of the RV-PA conduit for Norwood stage I palliation.

\section{References}

1. Sano S, Ishino K, Kado H, Shiokawa Y, Sakamoto K, Yokota M, et al. Outcome of right ventricle-to-pulmonary artery shunt in first-stage palliation of hypoplastic left heart syndrome: a multi-institutional study. Ann Thorac Surg. 2004;78: 1951-8.
2. Reemtsen BL, Pike NA, Starnes VA. Stage I palliation for hypoplastic left heart syndrome: Norwood versus Sano modification. Curr Opin Cardiol. 2007;22:60-5.

3. Nigro JJ, Bart RD, Derby CD, Sklansky MS, Starnes VA. Proximal conduit obstruction after Sano modified Norwood procedure. Ann Thorac Surg. 2005;80:1924-8.

4. Hasaniya NW, Shattuck H, Razzouk A, Bailey L. Modification of ventricular-to pulmonary shunt to minimize proximal conduit obstruction after stage I Norwood reconstruction. Ann Thorac Surg. 2010;89:e4-6.

5. Tanoue Y, Kado H, Shiokawa Y, Fusazaki N, Ishikawa S. Midterm ventricular performance after Norwood procedure with right ventricular-pulmonary artery conduit. Ann Thorac Surg. 2004;78:1965-71.

6. Cua CL, Sanghavi D, Voss S, Laussen PC, del Nido P, Marshall A, et al. Right ventricular pseudoaneurysm after modified Norwood procedure. Ann Thorac Surg. 2004;78:e72-3

\title{
Papillary heads "optimization" in repairing functional mitral regurgitation
}

\author{
Masashi Komeda, MD, PhD, Yutaka Koyama, Shunsuke Fukaya, and Hideki Kitamura, Nagoya, Japan
}

\footnotetext{
From the Department of Cardiovascular Surgery, Nagoya Heart Center, Nagoya, Japan.

Disclosures: Authors have nothing to disclose with regard to commercial support. Received for publication April 13, 2012; revisions received May 21, 2012; accepted for publication June 15, 2012; available ahead of print Aug 10, 2012.

Address for reprints: Masashi Komeda, MD, PhD, Department of Cardiovascular Surgery, Nagoya Heart Center, 1-1-14 Sunadabashi, Higashi-ku, Nagoya 461-0045, Japan (E-mail: komeda@ heart-center.or.jp).

J Thorac Cardiovasc Surg 2012;144:1262-4

$0022-5223 / \$ 36.00$

Copyright (C) 2012 by The American Association for Thoracic Surgery

http://dx.doi.org/10.1016/j.jtcvs.2012.06.038
}

During surgery for functional mitral regurgitation (FMR), tethering of the posterior mitral leaflet (PML) is a major cause of residual or recurrent FMR, especially after aggressive annuloplasty. ${ }^{1}$ We have previously described the concept of a novel repair technique and echocardiographic method. ${ }^{2}$ We report on the techniques and clinical outcomes.

\section{METHODS}

A total of 16 patients (mean age, $67.8 \pm 0.9$ years; 12 men, 6 with ischemic cardiomyopathy and 10 with nonischemic cardiomyopathy) 
had undergone surgery for FMR to alleviate heart failure in the previous 24 months. All the patients underwent standard cardiopulmonary bypass.

For each papillary muscle, the papillary heads that support the PML (posterior head) were approximated to the head that supports the anterior mitral leaflet (AML; anterior head) using pledgeted polytetrafluoroethylene sutures after placing annuloplasty sutures for better exposure (Figure 1,A). Next, the suture arms were passed through the midanterior mitral annulus using a large needle (Figure 1, B).

After mitral annuloplasty using a semirigid ring with the AML size, the sutures were passed through the ring and tied after length adjustment by pulling the sutures until the approximated papillary heads came 4 to $8 \mathrm{~mm}$ closer to the annulus (Figure 1, B).

The concomitant procedures included coronary artery bypass grafting in 5 patients, aortic valve replacement in 5, tricuspid annuloplasty in 3 , and the Cox-Maze procedure in 3 patients.

\section{RESULTS}

No hospital/late deaths or major complications occurred. The New York Heart Association functional class improved from $3.8 \pm 0.4$ preoperatively to $1.6 \pm 0.5$ at 1 month postoperatively $(P<.001$ vs preoperatively).

The hemodynamic results and left ventricular function/ dimension are listed in the Table 1. Postoperatively, FMR, left ventricular diastolic dysfunction, and AML tethering improved, and PML one did not aggravate. There was no finding of mitral stenosis.

The hemodynamic and clinical benefits were well maintained at the last follow-up visit. In the 7 patients with more than 12 months of follow-up, the New York Heart Association class was $1.6 \pm 0.5$, mitral regurgitation grade was $1.1 \pm 0.9$, left ventricular diastolic dysfunction was $56 \pm 9 \mathrm{~mm}$, and left ventricular ejection fraction was $38 \% \pm 17 \%$.

\section{DISCUSSION}

During surgery for FMR, PML tethering remains an unresolved issue. To our knowledge, the "chordal translocation" method, in which the anterior head of each papillary muscle was resuspended to the midanterior annulus using polytetrafluoroethylene sutures is the only method reported to alleviate PML tethering. ${ }^{3}$ However, its efficacy has been limited.

The "sandwich method," as reported by Ishikawa and colleagues, ${ }^{4}$ in which the anterior and posterior heads of each papillary muscle are simply approximated, motivated us to perform a pilot study using echocardiography and computed tomography. That study revealed that the AML and PML heads separated during systole in patients with FMR but they came closer during systole in healthy people.

Thus, we added the sandwich method to the chordal translocation to alleviate PML tethering more efficiently ("papillary head optimization"). Using this method, tethering of the AML was alleviated well and that of
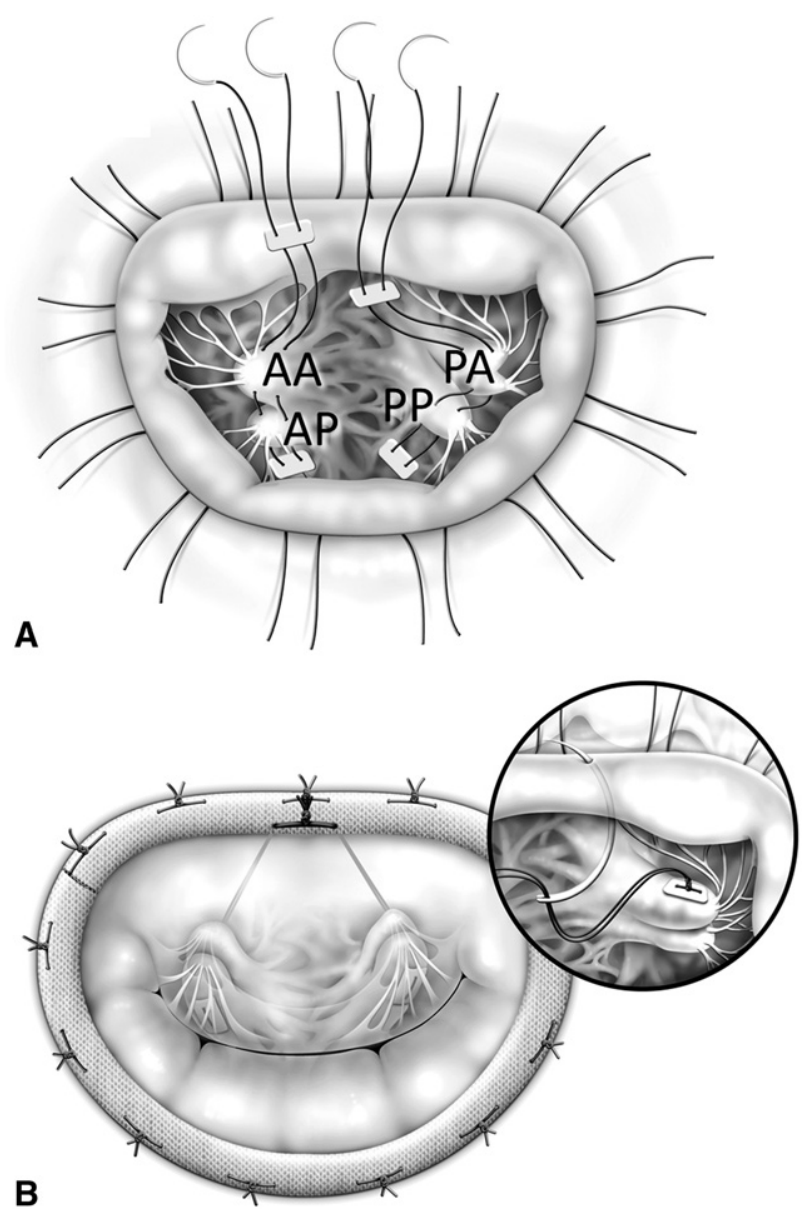

FIGURE 1. Surgical techniques for papillary head optimization. A, In each papillary muscle, the posterior head was approximated to the anterior head using polytetrafluoroethylene suture. $A A$, Anterior head of anterolateral papillary muscles; $A P$, posterior head of anterolateral papillary muscle; $P A$, anterior head of posterior papillary muscle; $P P$, posterior head of posterior papillary muscle. $\mathrm{B}$, The suture is passed through the midanterior mitral annulus and the annuloplasty ring.

the PML tended to improve. The benefit for the PML might be more obvious when we consider that PML tethering becomes worse after simple annuloplasty. ${ }^{1}$ However, if the preoperative left ventricular dysfunction is too extensive, the benefit of the surgery might be limited.

\section{CONCLUSIONS}

Papillary head optimization might help to alleviate posterior leaflet tethering and mitral regurgitation.

The authors express appreciation to Professor Kiyoshi Yoshida, MD, PhD, and Kikuko Obase, MD, PhD (Department of Cardiology, Kawasaki University Hospital) and Ms. Hiroko Ito, MT (Nagoya Heart Center) for their echocardiographic evaluation. 
TABLE 1. LV dimension/function and leaflets geometry

\begin{tabular}{|c|c|c|c|c|}
\hline & Variable & Preoperatively & Postoperatively & $P$ value \\
\hline \multirow{8}{*}{ LV } & MR (grade) & $3.5 \pm 0.5$ & $0.5 \pm 0.6$ & $<.001$ \\
\hline & LVDd (mm) & $63.2 \pm 8.2$ & $58.6 \pm 5.7$ & $<.005$ \\
\hline & LVEF $(\%)$ & $25.1 \pm 6.9$ & $29.8 \pm 10.6$ & NS \\
\hline & Tenting area $\left(\mathrm{cm}^{2}\right)$ & $1.7 \pm 0.6$ & $0.6 \pm 0.1$ & $<.001$ \\
\hline & AML angle $\left({ }^{\circ}\right), * 1$ & $42.9 \pm 8.5$ & $26.3 \pm 9.2$ & $<.001$ \\
\hline & PML angle $\left({ }^{\circ}\right), * 2$ & $65.2 \pm 11.2$ & $50.2 \pm 26.2$ & NS (.088) \\
\hline & PA pressure $(\mathrm{mm} \mathrm{Hg})$ & $51.4 \pm 19.6$ & $35.0 \pm 10.1$ & $<.01$ \\
\hline & LA-LV PG (mm Hg) & - & $2.3 \pm 1.1$ & \\
\hline
\end{tabular}

Postoperatively, posterior leaflet tethering tended to be ameliorated, just as was the anterior leaflet tethering. $A M L$, Anterior mitral leaflet; $P M L$, posterior mitral leaflet; $L A$, left atrium; $L V$, left ventricular; $L V D d$, left ventricular diastolic diameter; $L V E F$, left ventricular ejection fraction; $M R$, mitral regurgitation; $N S$, not significant; $P A$, pulmonary artery; $P G$, pressure gradient.

\section{References}

1. Zhu F, Otsuji Y, Yotsumoto G, Yuasa T, Ueno T, Yu B, et al. Mechanism of persistent ischemic mitral regurgitation after annuloplasty: importance of augmented posterior mitral leaflet tethering. Circulation. 2005;112(9 suppl):I396-401.

2. Obase K, Komeda M, Okura H, Yoshida K. A new echocardiographic window to visualize mitral valve complex during mitral valve repair for functional mitral regurgitation. J Thorac Cardiovasc Surg. 2012;143:e42-4.
3. Masuyama S, Marui A, Shimamoto T, Nonaka M, Yoshida K, Komeda M, et al. Chordal translocation for ischemic mitral regurgitation may ameliorate tethering of the posterior and anterior mitral leaflets. J Thorac Cardiovasc Surg. 2008; 136:868-75

4. Ishikawa S, Ueda K, Kawasaki A, Neya K, Suzuki H. Papillary muscle sandwich plasty for ischemic mitral regurgitation: a new simple technique. J Thorac Cardiovasc Surg. 2008;135:1384-6.

\title{
Sutureless technique for recurrent pulmonary vein stenosis after pericardial patchplasty in an adult
}

\author{
Masanori Hirota, MD, PhD, Joji Hoshino, MD, Yasuhisa Fukada, MD, and Tadashi Isomura, MD, PhD, \\ Kanagawa, Japan
}

Although percutaneous balloon dilation is recommended for patients with pulmonary vein (PV) stenosis induced by catheter ablation for atrial fibrillation, surgical correction would be indicated for patients with stenosis refractory to interventional therapy. For such patients, conventional pericardial patchplasty for PV stenosis has been performed, resulting in recurrent stenosis requiring reoperation. A successful case of postoperative PV stenosis repaired using a sutureless technique in an adult is reported.

From the Department of Cardiovascular Surgery, Hayama Heart Center, Kanagawa, Japan.

Disclosures: Authors have nothing to disclose with regard to commercial support.

Received for publication Feb 17, 2012; revisions received March 13, 2012; accepted for publication April 4, 2012; available ahead of print Aug 17, 2012.

Address for reprints: Masanori Hirota, MD, PhD, Department of Cardiovascular Surgery, Hayama Heart Center, 1898-1 Shimoyamaguchi, Hayama, Kanagawa 240-0166, Japan (E-mail: hirota @ hayamaheart.gr.jp).

J Thorac Cardiovasc Surg 2012;144:1264-6

$0022-5223 / \$ 36.00$

Copyright (c) 2012 by The American Association for Thoracic Surgery

http://dx.doi.org/10.1016/j.jtcvs.2012.04.025

\section{CASE REPORT}

A 41-year-old man developed from recurrent PV stenosis induced by frequent catheter ablation for atrial fibrillation. Three-dimensional computed tomography showed restenosis of the bare metal stent in the left upper PV, complete occlusion of the left lower PV (LLPV), severe stenosis of the right upper $\mathrm{PV}$, and mild stenosis of the right lower $\mathrm{PV}$ (Figure 1, A).

Under cardioplegic arrest, the left side of the left atrium was opened, and the bilateral PVs were inspected. The intima had grown extensively over the stent, covering the orifice of the LLPV. After removal of the stent, the left upper PV, LLPV, and right upper PV were reconstructed using patchplasty with autologous pericardium treated with $0.6 \%$ glutaraldehyde. Postoperative 3-dimensional computed tomography demonstrated a successful outcome with wide opening of the bilateral PVs (Figure 1, B).

At 5 months after the initial operation, restenosis of 3 repaired PVs was confirmed by 3-dimensional computed tomography. Reoperation was performed for recurrence 